\title{
Loss of $\alpha$-Calcitonin Gene-Related Peptide ( $\alpha$ CGRP) Reduces the Efficacy of the Vestibulo-ocular Reflex (VOR)
}

\author{
Anne E. Luebke, ${ }^{1}$ Joseph C. Holt, ${ }^{2}$ DPaivi M. Jordan, ${ }^{2}$ Yi Shan Wong, ${ }^{3}$ Jillian S. Caldwell, ${ }^{3}$ and Kathleen E. Cullen ${ }^{3}$ \\ ${ }^{1}$ Departments of Biomedical Engineering and Neurobiology \& Anatomy, University of Rochester Medical Center, Rochester, New York 14642, ${ }^{2}$ Departments \\ of Otolaryngology and Neurobiology \& Anatomy, University of Rochester Medical Center, Rochester, New York 14642, and ${ }^{3}$ Aerospace Medical Research \\ Unit, Department of Physiology, McGill University, Montreal, Quebec H3G 1Y6, Canada
}

The neuroactive peptide calcitonin-gene related peptide (CGRP) is known to act at efferent synapses and their targets in hair cell organs, including the cochlea and lateral line. CGRP is also expressed in vestibular efferent neurons as well as a number of central vestibular neurons. Although CGRP-null (-/-) mice demonstrate a significant reduction in cochlear nerve sound-evoked activity compared with wild-type mice, it is unknown whether and how the loss of CGRP influence vestibular system function. Vestibular function was assessed by quantifying the vestibulo-ocular reflex (VOR) in alert mice. The loss of CGRP in (-/-) mice was associated with a reduction of the VOR gain of $\approx 50 \%$ without a concomitant change in phase. Using immunohistochemistry, we confirmed that, although CGRP staining was absent in the vestibular end-organs of null (-/ ) mice, cholinergic staining appeared normal, suggesting that the overall gross development of vestibular efferent innervation was unaltered. We further confirmed that the observed deficit in vestibular function of null $(-/-)$ mice was not the result of nontargeted effects at the level of the extraocular motor neurons and/or their innervation of extraocular muscles. Analysis of the relationship between vestibular quick phase amplitude and peak velocity revealed that extraocular motor function was unchanged, and immunohistochemistry revealed no abnormalities in motor endplates. Together, our findings show that the neurotransmitter CGRP plays a key role in ensuring VOR efficacy.

Key words: CGRP; efferent; mouse; sensory coding; vestibular; vestibuloocular reflex

\section{Introduction}

Calcitonin-gene related peptide (CGRP), a 37 amino acid neuroactive peptide, is expressed in the auditory and vestibular systems (Wackym et al., 1993; Maison et al., 2003a; Ahn et al., 2009; Xiaocheng et al., 2013). In the central auditory system, CGRPpositive neurons can be found in the lateral superior olivary nucleus. Retrograde injection studies have shown that these same neurons send direct projections to the cochlea, comprising the lateral olivocochlear component of the auditory efferent system (Ohno et al., 1993). Similarly, in the central vestibular system, CGRP-positive neurons located in the region rostrocaudal to the vestibular nuclei project directly to the vestibular end-organs, comprising the E-group of the efferent vestibular system (EVS) (Ohno et al., 1993; Lysakowski and Goldberg, 2004). In the pe-

Received Aug. 5, 2013; revised June 29, 2014; accepted June 29, 2014.

Author contributions: A.E.L. and K.E.C. designed research; A.E.L., J.C.H., P.M.J., Y.S.W., J.S.C., and K.E.C. performed research; A.E.L. contributed unpublished reagents/analytic tools; A.E.L., J.C.H., P.M.J., Y.S.W., J.S.C., and K.E.C. analyzed data; A.E.L., J.C.H., P.M.J., and K.E.C. wrote the paper.

This work was supported by the McGill University Dawson Chair program, Natural Sciences and Engineering Research Council of Canada, Canadian Institutes of Health Research to K.E.C., National Institutes of Health Grants DC003086 to A.E.L. and DC008981 to J.C.H., and the Schmitt Foundation to A.E.L. We thank the Center for Navigation and Communication Sciences (National Institutes of Health P30-DC005409) and URSMD Confocal and Conventional Microscopy Core for use of the confocal microscope; Harrod Ling and Lisa Sun for help with data acquisition; Vladimir Grouza for critically reading the manuscript; and S. Nuara and W. Kucharski for excellent technical assistance.

The authors declare no competing financial interests.

Correspondence should be addressed to Dr. Anne E. Luebke, University of Rochester Medical Center, 601 Elmwood Avenue, Box 603, Rochester, NY 14642. E-mail: Anne_Luebke@urmc.rochester.edu.

DOI:10.1523/JNEUROSCI.3336-13.2014

Copyright $\odot 2014$ the authors $\quad 0270-6474 / 14 / 3410453-06 \$ 15.00 / 0$ riphery of both systems, CGRP colocalizes with ChAT, the enzyme that catalyzes the synthesis of acetylcholine (ACh). This colocalization is observed in the varicosities of efferent fibers, suggesting that CGRP and ACh function together to modulate peripheral auditory and vestibular sensory function. Moreover, although CGRP expression strongly colocalizes with key components of the vestibular and auditory efferent systems, its expression does not appear to be exclusive to these pathways. For example, CGRP-positive neurons have also been identified in the lateral lemniscus of the auditory system, as well as in the vestibular nuclei, nucleus prepositus, and vestibular cerebellum (Wackym et al., 1993; Ahn et al., 2009; Xiaocheng et al., 2013). To understand how CGRP influences auditory function, Maison et al. (2003b) tested a transgenic mouse with a targeted deletion of the $\alpha$ isoform of the CGRP gene, $\alpha C G R P(-/-)$-null. CGRP loss did not affect cochlear auditory thresholds or distortion-product otoacoustic emissions, yet mice showed a striking $\sim 20 \%$ reduction in suprathreshold cochlear nerve sound-evoked activity. It is not yet known whether or how the loss of CGRP influences vestibular system function.

Accordingly, here we examined the $\alpha C G R P(-/-)$-null mouse line. First, to assess the functional implications of $\alpha \mathrm{CGRP}$ loss, we characterized the vestibular-ocular reflex (VOR) and found a VOR gain reduction of $\sim 50 \%$. Immunohistochemistry demonstrated that CGRP staining was absent in the vestibular end-organs of $\alpha C G R P(-/-)$ mice, whereas ChAT staining in both vestibular end-organs and extraocular muscles was compa- 
rable with wild-type mice. Finally, combining the analysis of rapid eye movements and immunohistochemistry, we ruled out the possibility that this functional deficit is the result of a nonvestibular effect at the level of the extraocular motor neurons and/or their innervation of extraocular muscles. Collectively, our results suggest that CGRP plays a key role in ensuring VOR efficacy.

\section{Materials and Methods}

Animals. $\alpha$ CGRP-null $(-/-)$ and wild-type $(+/+)$ transgenic mouse lines were created and characterized by the Emeson laboratory on a pure 129SvEv background, shipped to the Luebke laboratory, maintained as heterozygotes, and genotyped using methods described by Lu et al. (1999). Mice, of either sex, have a targeted deletion of $\alpha$ CGRP, produced by tissue-specific alternative splicing of the calcitonin/ $\alpha$ CGRP gene while leaving the highly homologous $\beta$-CGRP gene intact (Lu et al., 1999). The loss of $\alpha$ CGRP in the vasculature of null animals was compensated by $\beta C G R P$, and was not associated with abnormalities in heart rate or blood pressure under basal or exercise-induced conditions, which could have been confounding issues in our study. A total of 24 mice ( 12 females/12 males) were used in this study. The $\alpha \operatorname{CGRP}(-/-)$ mice and their $\alpha C G R P(+/+)$ littermates (3-6 months old) were shipped to McGill for eye movement and vestibular testing. Care and use of the animals were approved by the University of Rochester Committee on Animal Resources and the McGill University Animal Care Committee and were in strict compliance with guidelines of the Canadian Council on Animal Care, United States Public Health Service regulations, and the Federal Animal Welfare Act.

Morphological/immunohistochemical studies. Mice were anesthetized with ketamine $(80 \mathrm{mg} / \mathrm{kg}) / x y l a z i n e ~(5 \mathrm{mg} / \mathrm{kg})$ and perfused with heparinized PBS followed by $4 \%$ PFA. Animals were then decapitated with head postfixed in $4 \%$ PFA overnight at $4^{\circ} \mathrm{C}$. Vestibular end-organs and eye muscles were subsequently dissected and placed in $30 \%$ sucrose $@ 4^{\circ} \mathrm{C}$. Tissues were embedded in 12\% gelatin:30\% sucrose, and $40 \mu \mathrm{m}$ frozen longitudinal sections were cut (i.e., along the long axis of the crista) on a freezing microtome (for canals, see Fig. $2 A$ ). Sections were blocked with 5\% normal donkey sera (Jackson ImmunoResearch Laboratories) and $0.5 \%$ Triton $\mathrm{X}$ in $0.1 \mathrm{M}$-phosphate buffer (PB), and then incubated with primary antibodies (see below) in PB overnight. After washing, tissue sections were reacted with the appropriate AlexaFluorconjugated secondary antibodies (Invitrogen) at 1:500 in PB for 2-3 h. To stain motor endplates in eye muscles, AlexaFluor-488-conjugated $\alpha$ BTX (Invitrogen; B1342, 1:500 dilution) was added with secondary antibodies. All sections were then washed in PB, stained with DAPI (10 $\mu \mathrm{g} / \mathrm{ml}$, Sigma), and mounted.

Primary antibody characterization. ChAT (Millipore; AB144P lot JC1618187, 1:100 dilution or lot NG1780580, 1:250-1:500 dilution) antibodies, generated against the human placental enzyme, were used to label both motor endplates in eye muscles and efferent innervation in vestibular end-organs. CGRP (MU33) antibody (gift from Ian M. Dickerson, 1:500 dilution) was generated against the amidated carboxyl 7 amino acids of rat $\alpha$ CGRP (Rosenblatt and Dickerson, 1997). Polyclonal antibodies against human myosin VIIa (Proteus Biosciences; \#25-6790, $10 \mu \mathrm{g} / \mathrm{ml}$ ) and rat calretinin (Millipore; AB5054 lot LV1552190, 1:500 dilution) labeled hair cells and calyx-only afferents, respectively.

Imaging/quantification. For visualization of labeled muscle tissue, an Axioplan2 Zeiss fluorescent microscope fitted with the Apotome system and $20 \times$ dry or $60 \times$ oil objectives were used to capture $Z$-stack images. Motor endplates were manually counted from 10 fields/animal in six animals $(3+/+, 3-/-)$. For labeled cristae, an Olympus FV1000 laser scanning confocal microscope (URSMD Light Microscopy Core) with a PLAPON $60 \times$ oil objective and sequential scanning option was used to capture images of labeled structures in the linear range. Maximum intensity projections were created using FV1000 software, and Adobe Photoshop and Illustrator were used to compile figures. For counting $\mathrm{ChAT}^{+}$ varicosities, six $400 \mu \mathrm{m}^{2}$ regions were placed over areas of ChAT labeling in single optical sections from the neuroepithelium of eight cristae $(4$ $+/+, 4-/-)$. For each canal, the number of $\mathrm{ChAT}^{+}$varicosities was averaged from counts taken in each of the six regions. Final counts were reported as mean \pm SEM.

Quantification of the VOR and main sequence. The surgical preparation for head implant surgery and experimental setup have been previously described (Vidal et al., 2004; Beraneck and Cullen, 2007). Eye movement data were recorded using an infrared video system (ISCAN) with optics modified for the mouse. The rotational velocity of the vestibular turntable (head velocity) was measured using an angular velocity sensor (Watson). Head and eye movement signals were low-pass filtered at $250 \mathrm{~Hz}$ and sampled at $1 \mathrm{kHz}$.

VOR eye movement responses, evoked by sinusoidally rotating headrestrained mice at frequencies of $0.2,0.5,1.0,2.0$, and $4.0 \mathrm{~Hz}, \pm 15^{\circ} / \mathrm{s}(15$ cycles of each frequency), were measured in darkness (peak head velocity was held constant because semicircular canals mechanically integrate head acceleration stimulus). Eye- and head-movement data were digitally low-pass filtered using a 51st-order finite-impulse-response filter (cutoff frequency $=40 \mathrm{~Hz}$ ), and eye position data were differentiated to obtain velocity traces. VOR gain and phase were determined by the leastsquares optimization (Beraneck et al., 2008) and are plotted as mean \pm SD across animals. All mice $(n=16)$ were tested at each frequency. Two-way ANOVAs and Bonferroni post tests were used to compare gains and phases for $(+/+)$ versus $(-/-)$ mice, at each test frequency. Cycles of data with quick phases were excluded from analysis of VOR dynamics. In addition, we analyzed the quick phases of vestibular nystagmus to characterize the linear relationship between peak quick phase velocity and amplitude (i.e., the main sequence) (Hübner et al., 2013).

\section{Results}

Vestibular function and quantification of the VOR

The VOR is a remarkably rapid motor response mediated by a well-defined pathway containing only three neurons. An advantageous feature of the VOR is that its dynamic response properties (i.e., gain and latency) can be precisely quantified and thus have been characterized in many species, including mice. To test our proposal that $\alpha \mathrm{CGRP}$ is critical for ensuring VOR efficacy, we quantified VOR response dynamics over the range of natural head movements. During exploratory activity, mice produce head movements for which component frequencies are mostly $\leq 4 \mathrm{~Hz}$ (Beraneck et al., 2008). Thus, we applied sinusoidal rotations over this frequency range. Figure $1 A, B$ shows examples of head-velocity stimuli and eye movement responses $(+/+$ and $-/-$ mice in blue and red, respectively), for 0.5 and $2.0 \mathrm{~Hz}$ head oscillations. In all experiments, mice were rotated in darkness and head velocity was kept constant at $15 \%$ s.

Figure $1 C, D$ shows Bode plots quantifying the frequency response of the VOR produced by whole-body rotation in the dark. In $(+/+)$ mice, the gain of evoked eye movements increased as a function of frequency, ranging from $0.17 \pm 0.02$ at $0.2 \mathrm{~Hz}$ to $1.0 \pm 0.05$ at $4 \mathrm{~Hz}$. In comparison, the VOR gains of $(-/-)$ mice were markedly reduced (by $\sim 50 \%$; Fig. $1 C$ ). The gain reduction was significant for all frequencies (Fig. $1 C$, inset). In contrast, response phases were comparable for both groups of mice at all frequencies (Fig. $1 D ; p>0.15$ ). Notably, the VOR led the stimulus at lower frequencies and was most compensatory for higher frequencies of stimulation approaching a lag of $\sim 5^{\circ}$ at $4.0 \mathrm{~Hz}$.

\section{Vestibular end-organ immunohistochemistry}

A light-microscopic examination revealed no obvious structural abnormalities in $\alpha C G R P(-/-)$ or $\alpha C G R P(+/+)$ animals in any vestibular end-organ (i.e., semicircular canal crista and otolithic macula), including hair cells, supporting cells, or afferent innervation.

Longitudinal sections of semicircular canal cristae from $\alpha C G R P(+/+)$ and $(-/-)$ animals were immunostained for CGRP and ChAT and visualized using confocal microscopy (Fig. 

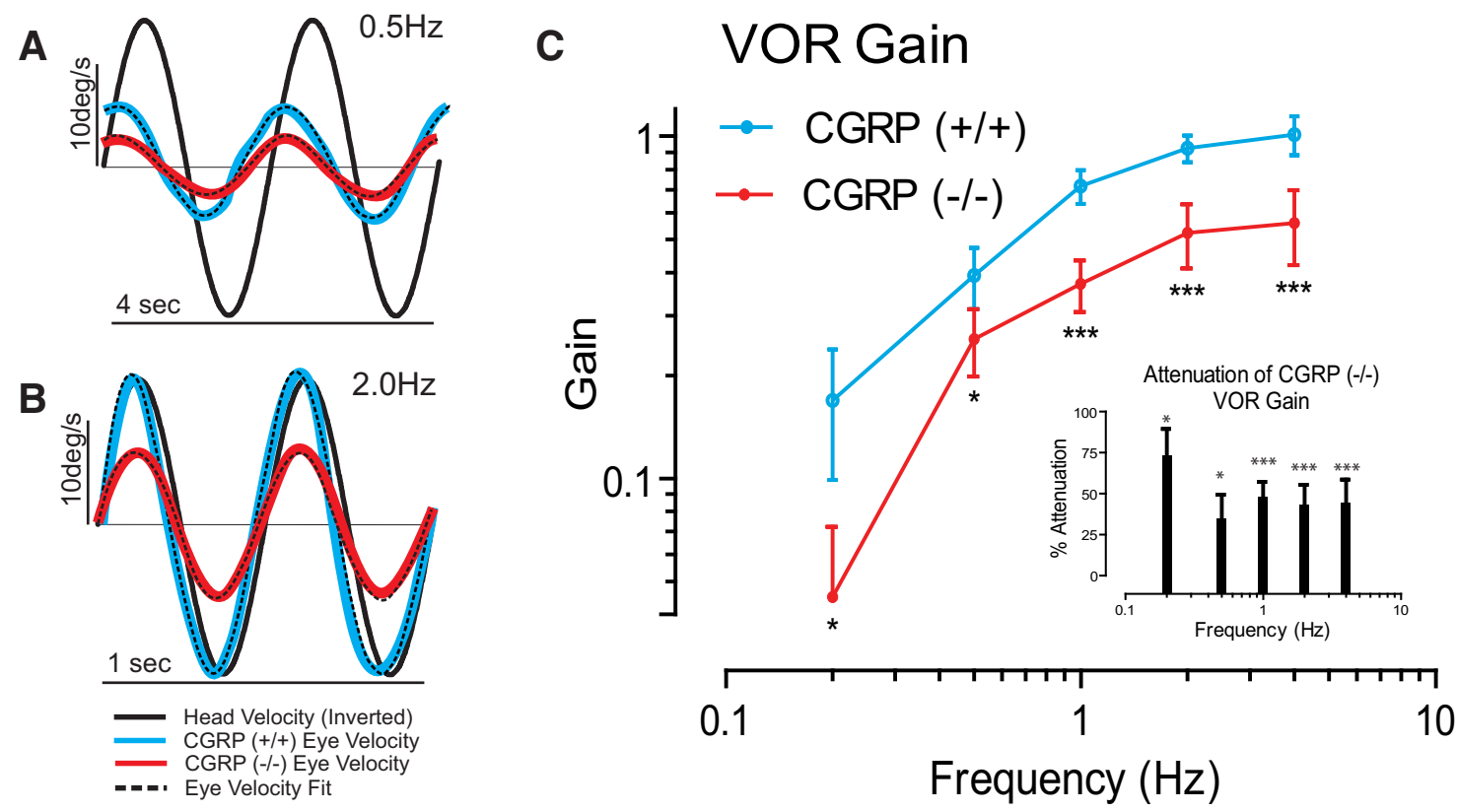

D VOR Phase

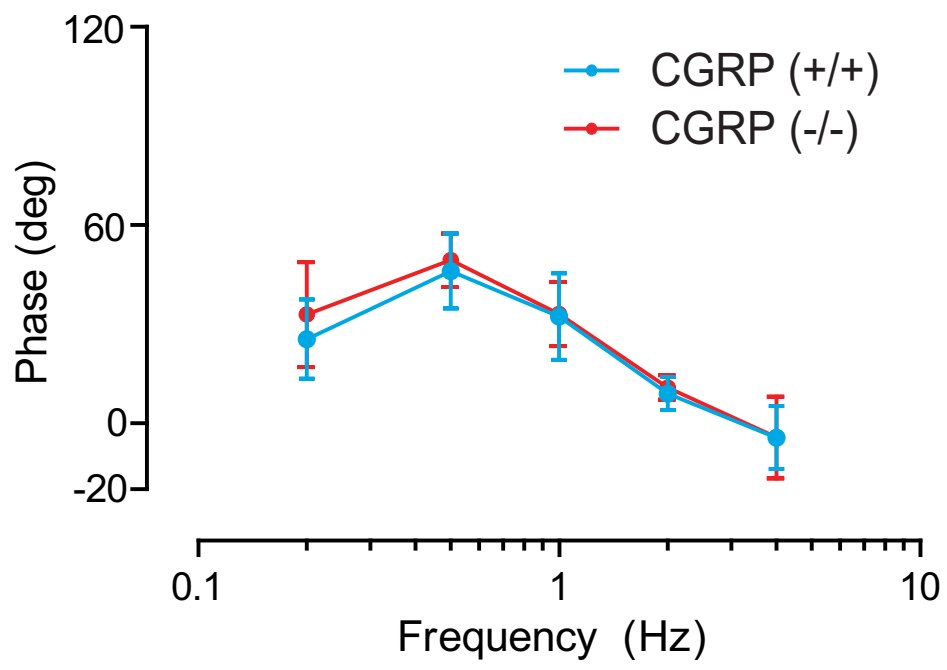

Figure 1. Loss of $\alpha$ CGRP reduces VOR gain without effects on VOR phase. $\boldsymbol{A}-\boldsymbol{D}$, VOR gain but not phase is reduced in $\alpha(G R P(-/-)$ mice $(n=8$ animals $/$ group; 4 males $/ 4$ females $)$. $\boldsymbol{A}, \boldsymbol{B}$, Examples of eye- and head-velocity (black) traces for $\alpha$ CGRP(-/-) (red) and $\alpha C G R P(+/+)$ mouse (blue) at 0.5 and $2.0 \mathrm{~Hz}$. C, VOR gain as a function of frequency (mean \pm SD). Inset, Percentage gain reduction measured in $(-/-$ ) versus $(+/+)$ mice. $\boldsymbol{D}$, VOR phase as a function of frequency (mean \pm SD). $\boldsymbol{C}, \boldsymbol{D}$, Data are mean \pm SD across animals (two-way ANOVA, $p<0.001$ significance of strain) with post hoc Bonferroni testing across frequency showing all frequencies affected. ${ }^{*} p<0.05$. ${ }^{* * *} p<0.001$.

2). Consistent with vestibular efferent innervation, fine $(\sim 1 \mu \mathrm{m})$ $\mathrm{ChAT}^{+}$fibers and associated spherical varicosities were identified in the neuroepithelium in close proximity to the base of calyx afferents and hair cells, labeled with calretinin and myosin7A, respectively (Fig. $2 B, C$ ). In $\alpha C G R P(+/+)$ mice, there was an extensive overlap in the distributions of CGRP and ChATimmunoreactive fibers and varicosities in horizontal cristae (Fig. $2 D, F)$. The overlap can be further appreciated by the highermagnification image in Figure 2I, in which immunoreactive varicosities positive for both ChAT and CGRP appear as yellow and orange.

Immunohistochemistry in $\alpha C G R P(-/-)$ mice revealed that CGRP-immunoreactive fibers and varicosities were absent in crista neuroepithelia (Fig. 2E, $G, J$ ). When images from CGRP and ChAT immunostaining were merged, only $\mathrm{ChAT}^{+}$fibers and varicosities were present (Fig. 2G,J). ChAT labeling, however, appeared similar between $\alpha C G R P(+/+)$ and $\alpha C G R P(-/-)$ mice (Fig. $2 F, G)$. Indeed, the number of $\mathrm{ChAT}^{+}$ varicosities per $400 \mu \mathrm{m}^{2}$ in $\alpha C G R P(-/-)$ mice was not significantly different from counts taken from $\alpha C G R P(+/+)$ mice $(11.2 \pm 0.5$ vs $11.3 \pm 0.7$; Fig. $2 H)$. Given that there is only a difference of three amino acids between mouse $\alpha$ CGRP and $\beta C G R P$ peptides, it is unlikely that our CGRP antibodies distinguished between these two isoforms. Thus, the loss of CGRP immunostaining in $\alpha C G R P(-/-)$ mice suggests that $\alpha \mathrm{CGRP}$ is no longer present in the EVS pathway and $\beta C G R P$ is not upregulated to compensate for the ablation of the $\alpha C G R P$ gene, as has been documented for the vasculature (Lu et al., 1999). The small $\mathrm{CGRP}^{+}$spots remaining in the null tissue may represent resident $\beta$ CGRP labeling (Fig. $2 J$ ). Similar punctate staining is also seen in 

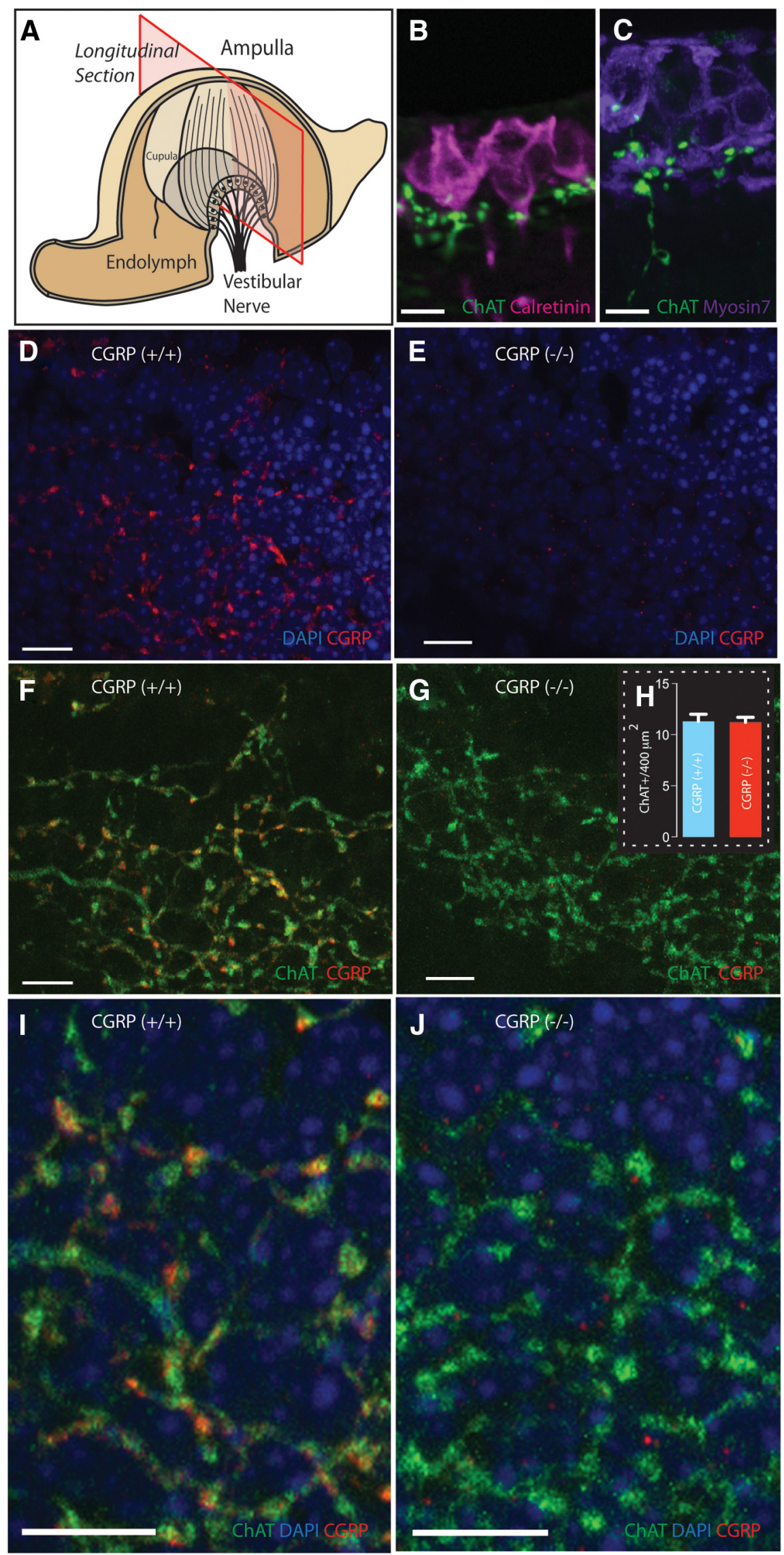

Figure 2. Loss of $\alpha$ CGRP does not alter the cholinergic EVS projection to the vestibular end-organs. $\boldsymbol{A}$, Plane of crista longitudinal section. $B, C, C h A T^{+}$varicosities, localized to the crista neuroepithelium in close proximity to calyx afferents and hair cells $\alpha C G R P(+/+)$ cristae, but neither shows much overlap with ChAT labeling. Comparable ChAT immunoreactivity between $\alpha C G R P(+/+)$ and $\alpha C G R P(-/-)$ mice suggests that the EVS pathway's general development and cholinergic innervation were unaltered by the loss of $\alpha$ CGRP.

\section{Confirmation of normal function and} histology at the level of the extraocular motoneurons and their projections to the eye muscles

One possible alternative explanation for the striking deficit in the VOR gain of $(-/-)$ mice is that it reflects a nonvestibular-related effect of $\alpha$ CGRP loss, occurring at the level of extraocular motoneurons and/or their innervations of extraocular muscles. Evidence that our results were not the result of such impairment was obtained from the analysis of vestibular nystagmus quick phases (Fig. $3 A$, inset, arrow). Notably, vestibular quick phases are produced by a premotor circuit largely separate from that producing the compensatory VOR (i.e., slow phase) (for review, see Cullen and Van Horn, 2011). In agreement with previous studies (McMullen et al., 2004), quick phase amplitude was proportional to quick phase peak velocity in $(+/+)$ mice (Fig. 3A, blue symbols). Moreover, we found that this relationship was comparable $(p=0.378)$ for $(-/-)$ mice (Fig. $3 A$, red symbols), suggesting that the deficit observed in the VOR gain of $\alpha C G R P(-/-)$ mice was not the result of a processing impairment at the level of the extraocular motoneurons and/or their innervations.

Finally, we obtained further evidence that our observations were not the result of an impairment of extraocular motoneurons and/or their innervation. Immunohistochemical analyses (Fig. 3B-E) and motor endplate counts (Fig. $3 F$ ) were performed on lateral rectus extraocular muscles. In $(+/+)$ mice, CGRP immunoreactivity (red) revealed thin punctuated

\section{$\leftarrow$}

stained with calretinin and myosin $7 A$, respectively. $\boldsymbol{D}-\boldsymbol{J}$, The broad projection network of efferent terminals is made possible by having sections that encompass much of the falling slopes of the crista $(\boldsymbol{A}) . \boldsymbol{D}, \boldsymbol{F}, \boldsymbol{I}, \mathrm{CGRP}$ is abundantly present in the neuroepithelium of $\alpha G \operatorname{GP}(+/+)$ mouse canal crista with a distribution overlapping $(\mathrm{ChAT}$ expression $(\boldsymbol{F}, \boldsymbol{I})$ as illustrated in the composite images. $\boldsymbol{E}, \boldsymbol{G}, \boldsymbol{J}$, CGRP is absent in the neuroepithelium of $\alpha \operatorname{GRP}(-/-)$ mouse canal crista, but ChAT expression appears normal $(\boldsymbol{G}, \boldsymbol{J})$. $\boldsymbol{H}$, Counts of efferent varicosities. Blue represents nuclei; red represents staining for CGRP; green represents staining of ChAT; yellow and orange indicate overlap. Scale bars, $10 \mu \mathrm{m}$. 

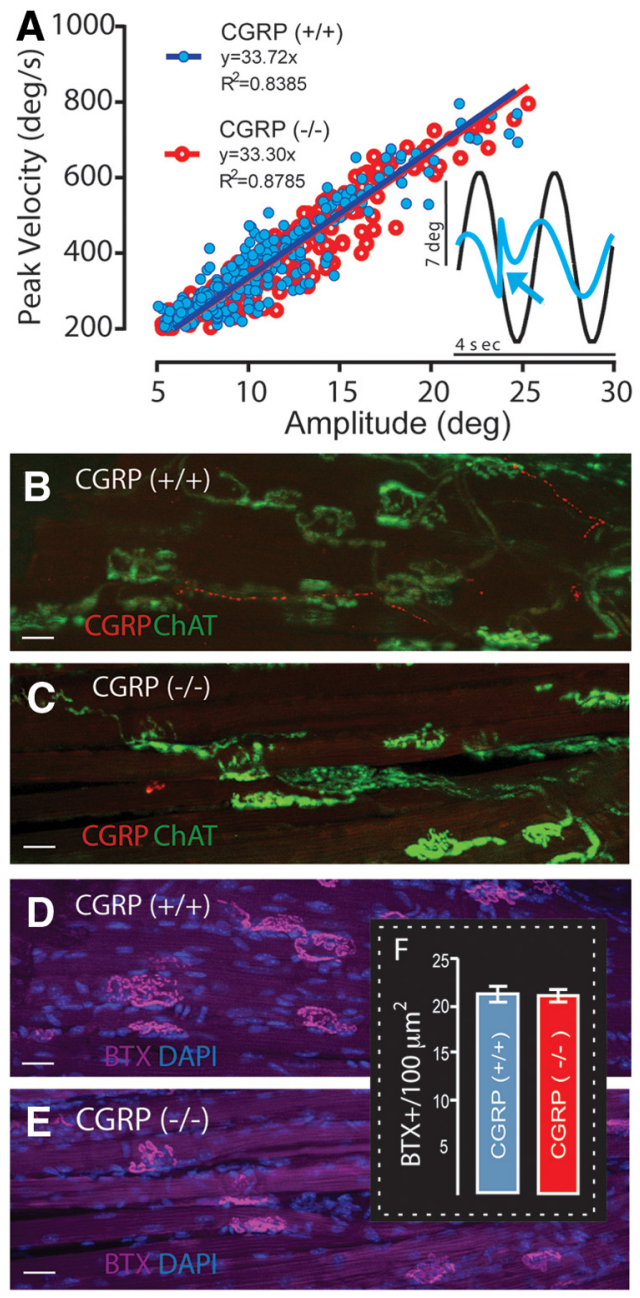

Figure 3. Loss of $\alpha \mathrm{CGRP}$ does not affect saccadic eye movement main sequence relationships or extraocular motor endplate densities. $\boldsymbol{A}$, Fast phase main sequence relationships are not affected by the loss of $\alpha \operatorname{CGRP}$ (compare $\alpha \operatorname{CGRP}(-/-)$ (red) and $\alpha \operatorname{GRP}(+/+)$ (blue)). Inset, Nystagmus quick phase (arrow). $\boldsymbol{B}-\boldsymbol{E}$, Extraocular lateral rectus motor endplates stained for CGRP and ChAT $(\boldsymbol{B}, \boldsymbol{C})$, and $\alpha \mathrm{BTX}(\boldsymbol{D}, \boldsymbol{E})$, with only CGRP reactivity absent in $\alpha C G R P(-/-)$ mice $(\boldsymbol{C}, \boldsymbol{E})$. Scale bars, $10 \mu \mathrm{m}$. The density and structure of extraocular motor endplates are similar qualitatively between $\alpha C G R P(+/+)(\boldsymbol{B}, \boldsymbol{D})$ and $(-/-)$ animals $(\boldsymbol{C}, \boldsymbol{E})$. $\boldsymbol{F}$, Numbers of $\alpha \mathrm{BTX}$-labeled motor endplates per $100 \mu \mathrm{m}^{2}$ are not affected by the loss of $\alpha \mathrm{CGRP}(n=3$ animals/group; 2 males/1 female/group; 10 fields/animal).

axons in the extraocular musculature coursing parallel to the muscle fibers. CGRP staining in the motor endplates was sparser than EVS projections to vestibular end-organs (Fig. 2). Extraocular muscles were also immunostained for ChAT and $\alpha$ BTX to label the presynaptic and postsynaptic components of the motor endplate, respectively. The overlap of ChAT (green) and $\alpha \mathrm{BTX}$ labeling (purple) was comparable in both $(+/+)$ and $(-/-)$ mice (Fig. 3B-E). Interestingly, in contrast to CGRP's EVS projection, CGRP and ChAT were not overlapping in the extraocular musculature (Fig. 3B).

Despite the lack of immunostaining for CGRP in $(-/-)$ mice (Fig. 3C), ChAT and $\alpha$ BTX labeling of presynaptic and postsynaptic components of the endplate did not reveal any obvious abnormalities in the motor endplates (Fig. $3 C, E$ ). The loss of $\alpha$ CGRP did not affect the general tortuous shape or size of endplates. Finally, quantification of motor endplate densities in extraocular muscles of $(-/-)$ and $(+/+)$ animals also revealed no differences, averaging $\sim 20$ endplates $/ 100 \mu \mathrm{m}^{2}$ in each group (Fig. 3F). Collectively, our behavioral (Fig. 3A) and histological findings (Fig. $3 B-F$ ) provide strong evidence that the marked reduction in VOR gain observed in $(-/-)$ mice did not result from a deficiency in processing at the level of extraocular motoneurons or their projections to eye muscles.

\section{Discussion}

In this study, we show that mice with targeted deletion of the $\alpha$ CGRP gene display a marked decrease in vestibular function. Specifically, the loss of $\alpha$ CGRP in alert ( $/-$ ) mice was linked to a $50 \%$ reduction in the VOR gain without concomitant changes in phase. Immunohistochemistry confirmed that CGRP was absent in vestibular end-organs of $(-/-)$ mice, whereas ChAT staining suggested that the gross development of the EVS was unaltered. Furthermore, histological analysis revealed no abnormalities in motor endplates of extraocular muscles, and analysis of the relationship between vestibular quick phase amplitude and peak velocity suggested that motor function was unchanged. Together, our findings suggest that the neurotransmitter CGRP plays a key role in ensuring VOR efficacy.

\section{CGRP and EVS function}

CGRP is strongly expressed in the peripheral EVS as well as in some central vestibular neurons (e.g., vestibular nuclei, prepositus hypoglossi, and vestibular cerebellum) (Wackym et al., 1993; Ahn et al., 2009; Xiaocheng et al., 2013). Interestingly, CGRPpositive neurons in vestibular nuclei that project to vestibular efferent nuclei could also potentially influence the EVS (Xiaocheng et al., 2013). In mammals, the EVS comprises $\approx 300-$ 400 parent neurons that project bilaterally and branch extensively in the periphery (for review, see Lysakowski and Goldberg, 2004). The functional role of the EVS remains unknown. Electrical and high-velocity stimulation of the mammalian EVS generates excitatory responses that are larger for more irregularly discharging canal afferents (Goldberg and Fernández, 1980; Marlinski et al., 2004; Sadeghi et al., 2009). It was initially postulated that the EVS might inhibit afferents in anticipation of intended movement, to preserve the peripheral coding range for unexpected head motion. Experiments in monkeys, however, have provided evidence against this idea (Sadeghi et al., 2007).

To date, our understanding of the functional role of the brain's efferent projection to the inner ear is largely limited to innervation of auditory periphery. The auditory efferent system can be divided into the medial (MOC) and lateral olivocochlear (LOC) systems (Warr and Guinan, 1979). MOC pathway stimulation releases $\mathrm{ACh}$ to hyperpolarize cochlear outer hair cells via activation of $\alpha 9 / \alpha 10 \mathrm{nAChRs}$ (Ballestero et al., 2011). In contrast, the LOC pathway innervates the dendrites of cochlear afferents just beneath inner hair cells, and its effect is mediated by the release of ACh, GABA, and CGRP (Maison et al., 2003a).

Whereas the MOC pathway is thought to play a primary role in protecting the cochlea from acoustic trauma (Maison et al., 2002), the LOC pathway appears to play an important role in maintaining balance between inputs from each ear (Darrow et al., 2006). The loss of $\alpha$ CGRP has no effect on the cochlea's sensitivity to damage from acoustic trauma consistent with the lack of $\alpha$ CGRP's role in the MOC pathway. However, loss of $\alpha$ CGRP produces a substantial (20\%) reduction of auditory nerve activity (Maison et al., 2003b). Interestingly, as in the vestibular system, CGRP and acetylcholine are colocalized in the LOC. It is thus notable that, in the present study, no changes were observed in the cholinergic EVS projection and varicosities of animals lacking $\alpha$ CGRP. This finding is analogous to studies of the auditory system of $\alpha C G R P(-/-)$ mice, reporting normal cochlear structure, 
cochlear auditory brainstem response, and distortion product otoacoustic emission thresholds.

Thus, there are parallels between the auditory and vestibular efferent pathways. On the one hand, similar to the MOC system, the EVS is characterized by the presence of $\alpha 9 / \alpha 10 \mathrm{nAChRs}$ on Type II hair cells (Luebke et al., 2005; Zhou et al., 2013). On the other hand, similar to the auditory LOC system, CGRP is widely expressed in the EVS. Moreover, the loss of $\alpha$ CGRP in both the LOC and EVS is linked to a decrease in functional efficacy (i.e., quantified by a reduction in afferent nerve response and VOR gain, respectively). This then raises the question of whether our current understanding of the LOC might provide insight into the function of the EVS.

Our results further suggest that the perturbations of the EVS preferentially influence the gain of the VOR while having minimal impact on its dynamics (i.e., phase). Interestingly, this parallels experimental observations in other species that vestibular afferent gain decreases during selective stimulation of efferent fibers, without concomitant dynamic changes (Goldberg and Fernández, 1980; Boyle and Highstein, 1990). However, it is also important to note that, although $\alpha$ CGRP loss is most striking in the periphery, CGRP-dependent effects in central vestibular circuitry likely also contribute to reduced efficacy of the VOR. Notably, CGRP is present in some vestibular nuclei cells that project to the EVS and likely regulate its function (Wackym et al., 1993; Chi et al., 2007; Ahn et al., 2009). Further, $\alpha$ CGRP loss from birth may also impair upstream mechanisms that mediate VOR plasticity (e.g., in the cerebellum) and/or compensation via changes to the peripheral and/or central pathways. Future experiments, aimed at understanding the role of $\alpha \mathrm{CGRP}$ in central vestibular function, will be required to fully elucidate the role of CGRPdependent modulation of the VOR.

\section{References}

Ahn SK, Khalmuratova R, Jeon SY, Kim JP, Park JJ, Hur DG, Balaban CD (2009) Colocalization of 5-HT1F receptor and calcitonin gene-related peptide in rat vestibular nuclei. Neurosci Lett 465:151-156. CrossRef Medline

Ballestero J, Zorrilla de San Martín J, Goutman J, Elgoyhen AB, Fuchs PA, Katz E (2011) Short-term synaptic plasticity regulates the level of olivocochlear inhibition to auditory hair cells. J Neurosci 31:14763-14774. CrossRef Medline

Beraneck M, Cullen KE (2007) Activity of vestibular nuclei neurons during vestibular and optokinetic stimulation in the alert mouse. J Neurophysiol 98:1549-1565. CrossRef Medline

Beraneck M, McKee JL, Aleisa M, Cullen KE (2008) Asymmetric recovery in cerebellar-deficient mice following unilateral labyrinthectomy. J Neurophysiol 100:945-958. CrossRef Medline

Boyle R, Highstein SM (1990) Efferent vestibular system in the toadfish: action upon horizontal semicircular canal afferents. J Neurosci 10:15701582. Medline

Chi FL, Jiao Y, Liu HJ, Wang J, Shi Y, Barr JJ (2007) Retrograde neuron tracing with microspheres reveals projection of CGRP-immunolabeled vestibular afferent neurons to the vestibular efferent nucleus in the brainstem of rats. Neuroendocrinology 85:131-138. CrossRef Medline

Cullen KE, Van Horn MR (2011) The Oxford handbook on eye movements (Liversedge SP, Gilchrist ID, Everling S, eds). Oxford: Oxford UP.

Darrow KN, Maison SF, Liberman MC (2006) Cochlear efferent feedback balances interaural sensitivity. Nat Neurosci 9:1474-1476. CrossRef Medline
Goldberg JM, Fernández C (1980) Efferent vestibular system in the squirrel monkey: anatomical location and influence on afferent activity. J Neurophysiol 43:986-1025. Medline

Hübner PP, Lim R, Brichta AM, Migliaccio AA (2013) Glycine receptor deficiency and its effect on the horizontal vestibulo-ocular reflex: a study on the SPD1J mouse. J Assoc Res Otolaryngol 14:249-259. CrossRef Medline

Lu JT, Son YJ, Lee J, Jetton TL, Shiota M, Moscoso L, Niswender KD, Loewy AD, Magnuson MA, Sanes JR, Emeson RB (1999) Mice lacking alphacalcitonin gene-related peptide exhibit normal cardiovascular regulation and neuromuscular development. Mol Cel Neurosci 14:99-120. CrossRef Medline

Luebke AE, Maroni PD, Guth SM, Lysakowski A (2005) Alpha-9 nicotinic acetylcholine receptor immunoreactivity in the rodent vestibular labyrinth. J Comp Neurol 492:323-333. CrossRef Medline

Lysakowski A, Goldberg JM (2004) Morphophysiology of the vestibular periphery. In: The vestibular system (Highstein SM, Popper A, Fay RR, eds), pp 57-152. New York: Springer.

Maison SF, Luebke AE, Liberman MC, Zuo J (2002) Efferent protection from acoustic injury is mediated via alpha9 nicotinic acetylcholine receptors on outer hair cells. J Neurosci 24:10838-10846. Medline

Maison SF, Adams JC, Liberman MC (2003a) Olivocochlear innervation in the mouse: immunocytochemical maps, crossed versus uncrossed contributions, and transmitter colocalization. J Comp Neurol 455:406-416. CrossRef Medline

Maison SF, Emeson RB, Adams JC, Luebke AE, Liberman MC (2003b) Loss of alpha CGRP reduces sound-evoked activity in the cochlear nerve. J Neurophysiol 90:2941-2949. CrossRef Medline

Marlinski V, Plotnik M, Goldberg JM (2004) Efferent actions in the chinchilla vestibular labyrinth. J Assoc Res Otolaryngol 5:126-143. CrossRef Medline

McMullen CA, Andrade FH, Stahl JS (2004) Functional and genomic changes in the mouse ocular motor system in response to light deprivation from birth. J Neurosci 24:161-169. CrossRef Medline

Ohno K, Takeda N, Tanaka-Tsuji M, Matsunaga T (1993) Calcitonin generelated peptide in the efferent system of the inner ear: a review. Acta Otolaryngol Stockh 501:16-20. Medline

Rosenblatt MI, Dickerson IM (1997) Endoproteolysis at tetrabasic amino acid sites in procalcitonin gene-related peptide by pituitary cell lines. Peptides 18:567-576. CrossRef Medline

Sadeghi SG, Minor LB, Cullen KE (2007) Response of vestibular-nerve afferents to active and passive rotations under normal conditions and after unilateral labyrinthectomy. J Neurophysiol 97:1503-1514. CrossRef Medline

Sadeghi SG, Goldberg JM, Minor LB, Cullen KE (2009) Efferent-mediated responses in vestibular nerve afferents of the alert macaque. J Neurophysiol 101:988-1001. CrossRef Medline

Vidal PP, Degallaix L, Josset P, Gasc JP, Cullen KE (2004) Postural and locomotor control in normal and vestibularly deficient mice. J Physiol 559:625-638. CrossRef Medline

Wackym PA, Popper P, Micevych PE (1993) Distribution of calcitonin gene-related peptide mRNA and immunoreactivity in the rat central and peripheral vestibular system. Acta Otolaryngol 113:601-608. CrossRef Medline

Warr WB, Guinan JJ Jr (1979) Efferent innervation of the organ of corti: two separate systems. Brain Res 173:152-155. CrossRef Medline

Xiaocheng W, Zhaohui S, Ka B, Junhui X, Lei Z, Feng X, Guoqing Y, Lining F, Zuoming Z (2013) The expression of calcitonin gene-related peptide and acetylcholine in the vestibular-related nucleus population of wildtype mice and retinal degeneration fast mice after rotary stimulation. J Mol Neurosci 51:514-521. CrossRef Medline

Zhou T, Wang Y, Guo CK, Zhang WJ, Yu H, Zhang K, Kong WJ (2013) Two distinct channels mediated by $\mathrm{m} 2 \mathrm{mAChR}$ and $\alpha 9 \mathrm{nAChR}$ coexist in type II vestibular hair cells of guinea pig. Int J Mol Sci 14:8818-8831. CrossRef Medline 